\title{
The effect of regional factors in the development of eco-innovations in the firm
}

\begin{abstract}
This research addresses the study of the effect of regional factors in the development of ecoinnovations in the firm. We assume the hypothesis of regional heterogeneity, that is, geographical factors and the regional heterogeneity play an important role in determining the innovations in the firms. In this line, we will approach our study from the perspective of Regional Innovation Systems (RIS). Therefore, our research question involves the evaluation of regional factors as determinants of eco-innovation developing in the firm. To examine these questions, the PITEC database that covers the period 2011-2013 was used. Overall, 5,461 firms have been employed for the ordinal logit regression model. This research contributes to the studies of eco-innovation, extending the investigation into drivers of eco-innovation, and highlights the impact that RIS has on the eco-innovative development in the firm. We find that the regional interaction and regional characteristics are key elements for the development of eco-innovation in firms. Thus, the density of companies in the region, the regional per capita income, and the existence of financing mechanisms are key elements for the eco-innovative development in the firm.
\end{abstract}

Keywords:

\section{Introduction}

A number of empirical studies have attempted to identify the determinants of the adoption of eco-innovation at the firm level (Doran and Ryan, 2016; Melander, 2018; Tang et al., 2018; Zubeltzu-Jaka et al., 2018). Recently, several theoretical approaches have proved the explanatory variables for eco-innovation drivers, suggesting that firms are influenced by internal resources and capabilities, and external factors focused on the effect of policies and regulations and stakeholders (Kiefer et al., 2019; Cainelli and Mazzanti, 2013; Constantini et al., 2017; Dangelico et al., 2017; Novellie et al., 2016; De Medeiros et al., 2014; Del Río et al., 2016; Triguero et al., 2013; Horbach et al, 2012; Kammerer, 2009; Rennings and Ziegler, 2004).

Among those external factors, from the perspective of the regional innovation system (RIS) the literature acknowledge that the mere fact of belonging to a geographical area, companies are exposed to regional elements that should encourage the adoption and development of innovations (Fritsch, 2002; Cooke et al., 2005). Thus, the density of firms, regional demand, 
and regional proximity, among others, have been factors that have had a positive impact on innovation in firms (Cooke et al., 2005; Oerlemans and Meeus, 2005; Fritsch, 2002). However, geographic and regional factors, which have been widely investigated in the literature of innovation, have been poorly studied in the literature of eco-innovation (Parto, 2000; ZubeltzuJaka et al. al., 2018). Although eco-innovation has important singularities with regard to innovation, for example, eco-innovation might generate a 'win-win' setup characterized by the compatibility of economic development and sustainable economy (Arena et al., 2017; Porter and Van der Linde, 1995), or the effect double externality (Bönte, and Dienes, 2013; De Marchi, 2011) or regulatory push/pull effect (Constantini et al., 2017; Doran and Ryan, 2017; Choi et al., 2016), etc., the regional perspective may be useful for creating a better understanding of the eco-innovations and serve as a basis for the analysis.

Therefore, this paper investigates whether regional factors have an impact in the adoption of eco-innovation in firms through a statistical analysis based on the Spanish Innovation Survey (PITEC) carried out in 2013. We study the 17 Spanish regions (autonomous communities) and a sample composed of 5461 Spanish firms. This paper aims to contribute to the regional and eco-innovation literature by addressing the gap identified above. Specifically, the first aim is to ascertain whether the belonging to a specific region leads firms to engage more with ecoinnovation. Second, it investigates whether the development of eco-innovations is stimulated by regional interactions, as a consequence of the existence in the region of a greater density of companies, and the proximity between regions. Finally it explores the regional characteristics themselves, either by the economic level of the region, measured in per capita income, or by the institutional implication in the development of eco-innovations.

In the next section, we present a concise overview of relevant literature on eco-innovation and regional innovation in order to generate hypotheses. The following section describes our research methodology, including data collection and measures. Afterwards, our data analysis and results are provided. Then, we present the discussion and managerial implications of the findings.

\section{Theoretical approach}

\subsection{Eco-innovation: definition and conceptualisation}

There are several definitions of the term eco-innovation. Carrillo-Hermosilla et al. (2010) consider eco-innovation as an innovation that is capable of producing environmental and sustainable products and services. Rennings (2000) and Kemp et al. (2006) affirm that ecoinnovation is the development of a product, process, service or organizational innovation and 
that the final objectives are the narrowing of pollution and the sustainability of the economy. In general terms, eco-innovation refers to innovation in new products, services or new business practices, necessary to create new business opportunities and benefits to the environment (Dangelico, 2016; Doran and Ryan, 2016). In fact, Horbach et al. (2012), Ambec et al. (2013), Tsai and Liao (2017), and Peiró-Signes and Segarra-Oña (2018) conclude that eco-innovation can be defined as a typology of innovation, which provides environmental benefits.

In contrast to other innovations, eco-innovations present some differences that make them unique and distinguishable from the broader concept of innovation. First, Bleischwitz (2009), Reid and Miedzinski (2008) and Doran and Ryan (2017) point out that eco-innovation must develop innovations that generate environmental improvements, obtaining a value for both the producer and the consumer. Also, eco-innovation must reach the market either by opening new business niches or by generating better competitive behaviour, implying a net environmental improvement; that is, the environmental situation is better with eco-innovation than without it.

Second, eco-innovation might generate a 'win-win' setup characterised by compatibility of economic development and sustainable economy (Arena et al., 2017; Porter and Van der Linde, 1995). In this way, Daddi et al. (2016) and Dangelico et al. (2017) pointed out the need for the setting of environmental objectives in the firms. This forces companies to invest in new technologies and more efficient production processes, thereby saving costs and providing social benefits from a more sustainable environment.

The third difference is that eco-innovations originate from environmental problems that need urgent solutions, and which imply an associated cost for private firms (Choi et al., 2016; Bönte, and Dienes, 2013; Foulon et al., 2002). In fact, even if innovation reduces social costs, this supposes higher costs for private companies (Boggia et al., 2018; Dangelico, 2016; Rehfeld et al., 2007). In particular, innovation takes a long time to develop, implying high costs of investment in $\mathrm{R} \& \mathrm{D}$, and an exhaustive investigation of the market. In this context, the environmental literature has called this effect double externality (Bönte, and Dienes, 2013; De Marchi, 2011; Porter and Van der Linde, 1995), which refers to the absence of incentives for firms to invest in eco-innovation. The reduction of environmental damage by innovators reduces the pressure on other polluting firms, since there is a social benefit, without the latter having to adopt any measures. Moreover, due to the characteristics of the public good of environmental knowledge, it is relatively easy to copy the first innovators without incurring the high research costs and risks that this entails.

The last difference is that while new technology solves environmental problems, environmental regulation and policy are mainly responsible for these environmental 
improvements (regulatory push/pull effect). Previous research shows the importance of environmental regulations and policies and the impact in the development of eco-innovation. (Constantini et al., 2017; Doran and Ryan, 2017; Choi et al., 2016; Grubb and Ulph, 2002; Jorgenson, 2009; Popp, 2003). Therefore, in the study of drivers in eco-innovation in the firm, is necessary to consider that the eco-innovation is incentivised not only by the market and consumers but also by regulations and policy.

\subsection{Regional innovation systems and the impact in firms}

Innovation System (IS) has emerged as focal points for innovation and technology, as well as facilitating the relationship and interaction between private companies, researchers and institutional actors (Patel and Pavitt, 1994). An IS can be defined as the set of institutions and firms within a geographic area, that interact with each other with the aim of carrying out activities aimed at generating and disseminating knowledge for the development of innovations. This definition takes into account three aspects: first, a 'system' where institutions and companies interact; second, the activities focused on innovation; and finally, the innovation systems that imply a geographical approach. The study of IS focuses on the main components of the system, such as private firms and public organisations, and investigates their mutual interactions as well as their relationships with the social and institutional framework in which the system is embedded (Lundvall, 2007).

While early definitions of innovation systems focused on the national context (Lundvall, 2007), the confirmation that the differences in the development of innovations not only prevail between the countries but also at a regional level, expanded the framework of studies on innovation systems to different geographical levels (Barrutia et al., 2014). Thus, the geographical heterogeneity of the space generates regional differences in the innovative capacity that Porter and Stern $(2002$, p.5) described as a region's "potential [...] to produce a stream of commercially relevant innovations. This capacity is not simply the realized level of innovation but also reflects the fundamental conditions, investments, and policy choices that create the environment for innovation in a particular location".

Behind this concept is the Regional Innovation Systems (RIS), that is, the perception that innovation itself is a localised and geographically bounded phenomenon (Barrutia, et al., 2014), and that innovation in its different forms involves a strict path-dependency (Buesa et al., 2006; Oerlemans and Meeus, 2005). It is also argued that competitive advantage in a global economy is often very local and arises from a concentration of highly specialized skills and knowledge, institutions, related businesses and clients in a particular region (Duranton and Puga, 2003). In this line, Oerlemans and Meeus (2005) and Cooke et al. (2005) have highlighted multiple 
regional factors that influence innovation, such as density and concentration of firms, regional proximity, investment in $\mathrm{R} \& \mathrm{D}$, demand in the region, investment in innovation, etc. In fact, Cooke et al. (2005) conclude that two aspects are the key in the regional innovation systems: the first, the regional interaction, which determines the economic and business dynamics of the region and the permeability of this with other regions; the second aspect is derived from the characteristics of the region itself.

\subsection{Hypotheses}

\subsubsection{Regional interactions and the impact in the eco-innovation of firms.}

A first factor of regional interaction is the agglomeration and density of companies in the region. Buesa et al. (2006) and Fritsh (2002) point out how localization, linked to the existence of skilled labour, and the joint location of suppliers and clients, produce increasing returns to scale in final production and greater productivity and growth. According to this approach, different studies have found that the agglomeration, or higher density of companies in a region, increase innovative production even after controlling for differences in human capital, the structure of the high-tech industry, and the university infrastructure of R\&D (Carlino et al., 2007). Duranton and Puga (2003) show that the agglomeration, or the greater density of companies, allows "sharing", for example, the exchange of facilities, winning over the variety of suppliers of inputs, and creating "learning". Storper and Venables (2004) indicate that the creation, accumulation, and dissemination of knowledge are also facilitated by the greater density of companies since closer contacts can be established. Close proximity, thus, becomes a condition for the dissemination of information that would otherwise be impossible or too expensive to code.

In this context, it is expected that the greater regional density of companies, facilitate the development of eco-innovation. Thus, the proximity between firms facilitates collaboration and cooperation between companies (Cooke et al., 2005), and as De Marchi (2011) points out, this is a key element in the development of eco-innovation. The greater proximity and interaction with suppliers and customers are the fundamental elements of the circular economy (Evans et al., 2017; Melander, 2018). Moreover, Bönte, and Dienes (2013), and De Marchi (2011) point out that the proximity to eco-innovators allows and facilitates the diffusion of sustainable technologies, and the adoption by companies of eco-innovations. In this sense, the ecoinnovation due to the characteristics of the public good of environmental knowledge, it is relatively easy to copy the first innovators without incurring the high research costs and risks that this entails. Additionally, it is expected that a greater density of companies will facilitate the development of eco-innovation, since, as pointed out previously, learning, dissemination 
of knowledge, and collaboration is the key element of eco-innovative development (Melander, 2017; Mazzanti and Zoboli, 2009). Hence, we propose:

Hla. The density of companies in the region has a positive impact on the eco-innovation in the firm.

A second factor of regional interactions to consider is the proximity between regions. We consider that the proximity between regions has a positive effect on the eco-innovative development of the firms. First, the proximity between regions has been considered a facilitator of innovation (Boschma, 2005). Thus, the networks of relations between regions allow receiving knowledge flows from neighbouring regions. This geographic proximity represents the physical distance between the actors. Oerlemans and Meeus (2005) point out that short distances favour collaboration, networking, interaction and innovation. Moreover, the proximity to the core of the interactions, allows having greater access to tacit and highly specialized knowledge, which translates into a higher probability of innovation. Therefore, this means that the regions closest to the central core can potentially benefit from this proximity and therefore, it is expected that this proximity will have a positive effect on eco-innovation developing. Second, regional proximity to regions with higher levels of environmental regulation produces a pull/push effect in the nearest regions, as an effect of assimilation of good practices and regulations of a sustainable economy (Triguero et al., 2018). Moreover, the regional proximity is an incentive to develop economic transactions. The economic transactions between regions with different levels of environmental regulation, produces a harmonizing effect, to facilitate commercial activities. Therefore, regional proximity produces assimilation of environmental regulations, which is a determining factor in the eco-innovative development of firms. Hence, we propose:

$H 1 b$. The proximity between regions has a positive impact on the eco-innovation in the firm.

\subsubsection{Regional characteristics and the impact in the eco-innovation of firms.}

A first regional characteristic is institutional proximity. Boschma (2005) defines institutional proximity as the social and cultural norms that regulate commercial and noncommercial relationships in a specific context. In fact, institutional proximity creates effective communication and collaboration and improves social and organizational relationships. At the regional level, the institutional and administrative presence regulates economic and social relations. In fact, regional institutions, through economic incentives have been a mechanism used for the development of innovation in the regions (Fritsch, 2002).

From the point of view of eco-innovation, the regions have mechanisms of action that range from the promotion of public environmental policy through various agencies to the use of 
various economic, legal, and regulatory instruments (Tsai and Liao, 2017; Zubeltzu-Jaka et al., 2018). In particular, Zubeltzu-Jaka et al. (2018) have highlighted the importance of regulation as an incentive element of eco-innovation in companies. Moreover, economic instruments (e.g., tax deductions for companies, public financing, taxation, and subsidies or aid that encourage eco-innovation) have been considered a pull regulation factor of eco-innovation (Porter and van der Linde, 1995; Tsai and Liao, 2017). Therefore, it is expected that greater institutional proximity, embodied in economic mechanisms, facilitate the development of eco-innovation in the region. Hence, we propose:

H2a. The institutional proximity in the region, through economic instruments, has a positive impact in the eco-innovation in the firm.

A second regional characteristic is the regional per capita income, which is expected to have a positive impact in the eco-innovation at the firm. First, there is a certain consensus that the market demand is a factor that facilitates eco-innovation (Horbach et al., 2012; Tsai and Liao, 2017). In this line, and considering the per capita income an incentive of regional demand (Autores), we hope that high per capita income has a positive impact on eco-innovation in the firm. Second, a higher per capita income is related to the increase in consumption demand of intangibles. Asheim and Coenen (2005) pointed out that consumers demand eco-innovative products because of their intangibility component (for example, in the case of agro-industrial products, the consumer is willing to pay an extra cost if this is an ecological product). Third, following Arena et al. (2017), eco-innovation generates a 'win-win' setup characterised by compatibility of economic development and sustainable economy. In this context, higher income per capita is related to greater environmental care (Horbach et al., 2012; Kammerer, 2009; Kesidou and Demirel, 2012; Koontz et al., 2015), which will encourage demand to activate eco-innovative development in companies. Therefore, a positive impact on ecoinnovative development of firms is expected in regions with a high per capita income. Hence, we propose:

$H 2 b$. The per capita income in the region has a positive impact on the eco-innovation in the firm.

\section{Research Methodology}

3.1. The context: Spain and the regions 
For our study, we consider the regional classification NUTS $2^{1}$, which for the case of Spain is composed of 17 autonomous communities. In Spain, eco-innovation is generally embedded in national and regional policies targeting resource efficiency, eco-innovations, clean technologies and sustainable development. Thus, the promotion of the environmental public policy is carried out through the local Environmental Ministry and their dependent Autonomous Organisms.

\subsection{Data and variables}

In this research, the unit of analysis is the firm, and the data is collected from the Spanish Innovation Survey (PITEC, 2013). This survey is a database that allows the monitoring of technological innovation activities of Spanish companies. PITEC collects biannually all the innovation data of Spanish companies. PITEC contains firm-level data and it provides information about the company (employment, sales, geographic market, industry sector, etc.) as well as detailed information regarding its innovation activity (innovation expenditures, different kinds of innovation output, cooperation between firms, public financial support, barriers to innovation, and so on).

The survey is conducted bi-annually by the National Statistics Institute (INE) and replicates the questionnaire used by the Community Innovation Survey (CIS). The reference period of PITEC 2013 is 2011-2013, after filtering missing values and mergers, our working sample includes 5,461 Spanish firms.

\subsubsection{Dependent variable}

The PITEC questionnaire measures the eco-innovation of the firm through four items related with the innovative activity carried out in the company oriented towards the following environmental activities: i) Less energy per production; ii) Lower environmental impact; iii) Improvement in health and safety; and iv) Compliance with regulatory, environmental, health, or safety requirements. The eco-innovations are rated on a scale of 1 to 4 : a value of 1 is assigned if the eco-innovations activities is high; 2 if it is intermediate; 3 if it is low; and 4 if it is null. Based on these four categories, following Arranz et al. (2019), we generate one variable, eco-innovation, as a sum of the four previous variables. This new variable measures whether the company has successfully engaged in any of the four types of eco-innovation, and therefore, gather the diversity of eco-innovations developed by the company. Moreover, como

\footnotetext{
${ }^{1}$ Nomenclature of Territorial Unit for Statistics (NUTS, Eurostat, 2019). The NUTS is the official division of the EU for regional statistics. Europe is divided in 276 regions at NUTS level 2 (https://ec.europa.eu/eurostat/web/products-manuals-and-guidelines/-/KS-GQ-14-006).
} 
consecuencia de que the four variables are correlated (Alpha de Cronbach: 0.996), we also measure con la variable eco-innovacion the intensity of the firm's eco-innovation ${ }^{2}$.

\subsubsection{Independent variables}

The first variable, categorical variable, identifies each company with the one Autonomous Community it belongs. We consider the 17 Autonomous Communities of Spain, each of which has assumed political and institutional responsibilities in its region.

The second variable is the Per Capita Consumer Income in region $i$, which gives an idea of what the demand is in that region. Per capita income is obtained by dividing the GDP of the region by the number of inhabitants (Fritsch, 2002).

The next independent variable is the Density of Companies in the region $i$. The ratio is obtained by dividing the number of companies in the region by the surface expressed in $\mathrm{Km}^{2}$ (Oerlemans and Meeus, 2005).

The fourth variable is the location of the region $i$ in the national context (Regional Distance). According to Buesa et al. (2018), Madrid is the leading Community in Spain in the total index of innovation; thereby it is the distance with that region that is taken as reference. This variable is measured as the logarithm of geographic distance between each region and the Autonomous Community of Madrid.

Finally, institutional proximity was measured through the mechanisms of Public Financing in the region $i$. This variable emerges as a construct of three variables (PITEC, 2013): (1) subsidies from the local and autonomous administrations; (2) expenses in internal R\&D financed with public funds (from the autonomous administrations); and (3) financing for innovation obtained from local and autonomous administrations (Cronbach's Alpha=0.801).

\subsection{Control variables}

We include a number of control variables regarding structural characteristics of the firms. Previous empirical studies have found firms' size to be a determining factor in the ecoinnovation propensity (Hemmelskamp, 1999). Larger firms are more likely to engage in ecoinnovations compared to smaller firms due the complexity of such innovations and the investments needed to adopt cleaner technologies. As is standard in management literature, we measure the firm size with the log of the number of employees.

\footnotetext{
${ }^{2}$ To check whether the new variable measures the intensity of eco-innovation, we perform a Principal Components Analysis (ACP) with rotation Varimax, obtaining a single factor for the four variables. This analysis explains $90.851 \%$ of the variance $(\mathrm{KMO}=.868$, sig $=.000)$, with a contribution per variable: $0.846,0.925,0.931$, and 0.931. Later, we analysed the correlation degree between the variable eco-innovation obtained as sum, and the one obtained through the ACP. The result of this analysis indicated a high correlation (0.937), and the affinity or similarity between the two variables, being able to accept the measure of intensity.
} 
We control also for the sector by including a dummy variable that measures whether the company belongs to the manufacturing or services sector (Cai and Zhou, 2014; Horbach, 2008). The variable takes the value 0 if the firm belongs to the manufacturing sector, and 1 if it belongs to the service sector.

We control for the effect of the technological intensity of the different companies included in the sample (Gilsing et al., 2008). For this purpose, we measure the technological intensity by dividing the internal $R \& D$ expenditure by the number of people in the company.

A further control was for the international scope of the firm. PITEC questionnaire distinguishes four different geographical markets: i) local; ii) national; iii) EU; or iv) other countries. This variable takes the value 0 if it operates in the local or national market, 1 if is in the EU market exclusively, and 2 if it operates in the US and other markets (China and India).

We finally control for whether the firm belongs to a group (Cainelli et al., 2012). In this case, the questionnaire includes a dummy variable (Group): The variable takes the value 0 if the firm does not belong to a group and 1 if it does.

\subsection{Estimation models}

To test our hypotheses we exploit a twofold econometric strategy. First, we investigate the eco-innovation of firms (dependent variable) in the different autonomous communities (categorical variables) as shown in Table 2. To this end we estimated an Ordinal Logistic Regression Model as follows:

Model 1:

$y=$ constant $+\beta_{1}($ Firm Size $)+\beta_{2}($ Manufacturing/Services $)+\beta_{3}($ Technological

Intensity $)+\beta_{4}($ InternationalScope $)+\beta_{5}($ Group $)+e$

Model 2:

$y=$ constant $+\beta_{1}($ Autonomous Community $)+\ldots+\beta_{17}\left(\right.$ Autonomous Community $\left.{ }_{17}\right)+\beta_{18}($ Firm Size $)+\beta_{19}($ Manufacturing/Services $)+\beta_{20}($ Technological Intensity $)+\beta_{21}($ International Scope $)+$ $\beta_{22}($ Group $)+e$

The second part of our empirical analysis addresses Hpotheses 1a, 1b, 2a and 2b, that is, whether the regional interaction and characteristics influence the eco-innovation of firms (Table 3). In order to implement the analysis the independent variables are the twofold set of regional interaction and characteristics identified above (Density, Regional Distance, Public Financing and Per Capita Income). The equation models are as follows:

Model 3:

$y=$ constant $+\beta_{1}($ Firm Size $)+\beta_{2}($ Manufacturing/Services $)+\beta_{3}($ Technological

Intensity $)+\beta_{4}($ International Scope $)+\beta_{5}($ Group $)+e$ 
Model 4:

$y=$ constant $+\beta_{1}($ Density $)+\beta_{2}($ Firm Size $)+\beta_{3}($ Manufacturing $/$ Services $)+\beta_{4}($ Technological Intensity $)+\beta_{5}($ International Scope $)+\beta_{6}($ Group $)+e$

Model 5:

$y=$ constant $+\beta_{1}($ Regional Distance $)+\beta_{2}($ Firm Size $)+\beta_{3}($ Manufacturing/Services $)+$ $\beta_{4}($ Technological Intensity $)+\beta_{5}($ International Scope $)+\beta_{6}($ Group $)+e$

Model 6:

$y=$ constant $+\beta_{1}($ Public Financing $)+\beta_{2}($ Firm Size $)+\beta_{3}($ Manufacturing/Services $)+$ $\beta_{4}($ Technological Intensity $)+\beta_{5}($ International Scope $)+\beta_{6}($ Group $)+e$

Model 7:

$y=$ constant $+\beta_{1}($ Per Capita Income $)+\beta_{2}($ Firm Size $)+\beta_{3}($ Manufacturing/Services $)+$ $\beta_{4}($ Technological Intensity $)+\beta_{5}($ International Scope $)+\beta_{6}($ Group $)+e$

\section{Results and Discussion}

Table 1 shows the descriptive statistics of our sample. It shows that more than a half of the companies (69.9\%) developed at least one eco-innovation activity. In general, it is observed that eco-innovations are performed mainly in medium and large companies, in those with an international scope and those that belong to a group. Additionally, the results highlight that the availability of public funding favours the eco-innovation in the firm.

Table 2 shows the effect of belonging to a specific Autonomous Community in the developing of firm's eco-innovation. In general, it is observed that there is a different effect depending on the Autonomous Community in which the firm is located. These results corroborate previous literature on the existence of regional differences in terms of ecoinnovation (Authors), showing therefore the need to complement the studies that analyse both the effect of the stakeholder and regulations, with the inclusion of regional variables to understand the drivers of eco-innovation in the firm.

Table 3 reports the results for the regression analysis investigating the effect of the regional variables on eco-innovation in the firm. Regarding the variables of interaction, such as the density of the companies in the region, and regional proximity, we observe a different result. In the case of Hypothesis 1a, which shows the effect of density of the firm on eco-innovation, Model 4 shows that the density of the company has a positive effect $(B=0.135 ; \mathrm{p}<0.01)$ on eco-innovation, corroborating the hypothesis. The results show that a greater density of companies will facilitate the development of eco-innovation, highlighting that learning, dissemination of knowledge, and collaboration between firms are key elements of eco- 
innovative development (Melander, 2017; De Marchi, 2011; Mazzanti and Zoboli, 2009). However, our results do not support the Hypothesis 1b, as shown in Models 4 and 6, that regional proximity facilitates innovative developments (Boschma, 2005). In the case studied, a reason could be the short geographic distance between Spanish regions. A second reason could be that the power acquired by the regional governments tends towards an imbalance situation, in which there is greater independence among the different regions and a decrease in the importance of the interaction between them, unlike the central government which tends to homogenize the various policies throughout the territory.

Regarding the variables that consider the characteristics of the region in their effect on ecoinnovation, the results support both hipotheses. Thus, Hypothesis 2a, as shown in Model 5 in Table 4, revealed a positive and significant effect of public financing ( $(=0.050 ; p<0.01)$ in the development of eco-innovation. This evidence is in line with the previous literature that states that public financial resources encourage eco-innovation (for example, Horbach, 2008). Specifically, the results suggest that regional governments, through economic instruments, are a pull factor for developing the eco-innovation in the firm (Tsai and Liao, 2017, Porter and van der Linde, 1995). In reference to Hypothesis $2 b$, the analysis confirms that per capita income in the region has a positive effect $(\beta=5.307 \mathrm{E}-5 ; \mathrm{p}<0.01)$ in the development of eco-innovation in the firm. This finding is in line with the results emerging in the environment innovation literature which has consistently found that the greater the per capita income, the greater the environmental concern, and the higher the valuation of products with a big intangible component (Tesla et al., 2011).

\section{Conclusions}

The main objective of this paper was to analyse the impact of regional factors in the adoption of eco-innovations in the firm. These aspects have important implications both from a theoretical point of view and from the development of policies.

Although our results are specific to our study context, they contribute to the stream of literature in eco-innovation that investigates the drivers of eco-innovation. The literature suggests that on the development of eco-innovation, firms are influenced by both their resources and capabilities, the effect of policies and regulations, as well as by the stakeholders groups (Kiefer et al., 2019; Dangelico et al., 2017; Cainelli and Mazzanti, 2013; Constantini et al., 2017; Novellie et al., 2016; De Medeiros et al., 2014; Del Río et al., 2016; Triguero et al., 2013; Horbach et al, 2012; Kammerer, 2009; Rennings and Ziegler, 2004). However, our results support that Regional Innovation Systems (RIS) have an impact on the eco-innovative 
development in firms. Our research contributes to the theoretical framework for the empirical analyses of the drivers of the eco-innovation in the firm, combining the insights from the ecoinnovation approach and the regional perspective. In doing so, the paper bridges two streams of literature which so far has been separated. Our study also extends our knowledge on ecoinnovation drivers by addressing the impact of regional factors in the eco-innovations activities of the firm. The findings show that the density of companies, the per capita income, and the existence of financing mechanisms in the region are key elements of eco-innovative development in the firm. However, unlike innovation studies, regional proximity between regions does not have an impact on firm's eco-innovation.

These findings have also implications from the viewpoint of environmental innovation policies. Our evidence suggests the regional public funding as a stimulus to eco-innovation activities in firms. Environmental innovation policy should recognise this effect in the design and implementation of regional innovation systems. In this context, the eco-innovation policy should involve both the regional agents and the geographic space in which they act, developing the interactions between agents and creating the adequate framework to facilitate the achievement of eco-innovation objectives of firms. These actions, for example, might encompass the development of regional incentive policies for eco-innovation, or favour the clustering of firms.

In addition, a series of actions should be taken to mitigate the effects of certain structural characteristics of Spanish firms to favour their eco-innovation activities. For example, Marin et al. (2015) note that SMEs assume a reactive position (compliance with regulatory requirements), but not a proactive one in the development of eco-innovations. Therefore, policies that encourage the specific establishment of partnerships and interactions among SMEs for the development of environmental innovations should be developed. Additionally, public administrations should give preferential treatment to SMEs. Regarding regular innovations, collaboration agreements have demonstrate the increasing of skills and financial resources of SMEs, reducing the gap between large and small companies in terms of innovation. In this sense, cooperation for the development of eco-innovations may allow economies of scale and scope, as well as the reduction of the uncertainty by share the risks both in the results and the duration of the eco-innovation processes.

Finally, like any other, our study is not free from limitations. We have studied the Spanish case. In the context of Europe, Spain is below the European average in the development of ecoinnovation products, occupying the ninth position (Triguero et al., 2013). In addition, the presence of SMEs is comparatively more important in the productive structure of Spain, and 
these companies have a lower perception of the benefits of environmental management than the larger companies (Del Rio, 2005; Jové-Llopis and Segarra-Blasco, 2018). These factors could introduce biases in our analysis, for which the study should be expanded to countries. An additional point concerns the availability of data on eco-innovation and regional characteristics. Our dataset does not provide fine-grained information to capture other actors/factors that may play a relevant role in this regard (for example investors, final consumers and industrial clients, input suppliers, market and non-marked pressures, etc.). We hope that future research will capture these aspects.

\section{References}

Arranz, N., Arroyabe, M. F., Molina-García, A., \& de Arroyabe, J. F. (2019). Incentives and inhibiting factors of eco-innovation in the Spanish firms. Journal of Cleaner Production220, 167-176.

Asheim B.T. \& Coenen L. (2005) Knowledge Bases and Regional Innovation Systems: Comparing Nordic Clusters. Research Policy, 34, 1173-1190.

Barrutia, J. M., Echebarria, C., Apaolaza-Ibáñez, V., \& Hartmann, P. (2014). Informal and formal sources of knowledge as drivers of regional innovation: digging a little further into complexity. Environment and Planning A, 46(2), 414-432.

Borghesi, S., Cainelli, G., \& Mazzanti, M. (2015). Linking emission trading to environmental innovation: evidence from the Italian manufacturing industry. Research Policy 44, 669-683.

Boschma, R. (2005). Proximity and innovation: a critical assessment. Regional Studies, 39(1), 61-74.

Bossle, M. B., de Barcellos, M. D., Vieira, L. M., \& Sauvée, L. (2016). The drivers for adoption of eco-innovation. Journal of Cleaner Production, 113, 861-872.

Buesa, M., Heijs, J., Pellitero, M. M., \& Baumert, T. (2006). Regional systems of innovation and the knowledge production function: the Spanish case. Technovation, 26(4), 463-472.

Cai, W.G., \& Zhou, X.L. (2014). On the drivers of eco-innovation: empirical evidence from China. Journal of Cleaner Production, 79, 239-248.

Cainelli, G., \& Mazzanti, M. (2013). Environmental innovations in services: Manufacturingservices integration and policy transmissions. Research Policy, 42(9), 1595-1604.

Carlino, G. A., Chatterjee, S., \& Hunt, R. M. (2007). Urban density and the rate of invention. Journal of Urban Economics, 61(3), 389-419.

Cooke, P., Clifton, N., \& Oleaga, M. (2005). Social capital, firm embeddedness and regional development. Regional Studies, 39(8), 1065-1077. 
Costantini, V., Crespi, F., \& Palma, A. (2017). Characterizing the policy mix and its impact on eco-innovation: A patent analysis of energy-efficient technologies. Research Policy, 46(4), 799-819.

Dangelico, R.M. (2016). Green product innovation: where we are and where we are going. Business Strategy and the Environment 25(8), 560-576.

Dangelico, R. M., Pujari, D., \& Pontrandolfo, P. (2017). Green product innovation in manufacturing firms: A sustainability-oriented dynamic capability perspective. Business Strategy and the Environment, 26(4), 490-506.

De Marchi, V. (2012). Environmental innovation and R\&D cooperation: Empirical evidence from Spanish manufacturing firms. Research Policy, 41(3), 614-623.

Del Río, P. (2005). Analysing the factors influencing clean technology adoption: a study of the Spanish pulp and paper industry. Business Strategy and the Environment, 14(1), 20-37.

Del Río, P. (2009). The empirical analysis of the determinants for environmental technological change: A research agenda. Ecological Economics, 68(3), 861-878.

Del Río, P., Peñasco, C., \& Romero-Jordán, D. (2015). Distinctive features of environmental innovators: an econometric analysis. Business Strategy and the Environment, 24(6), 361385 .

Doran, J., \& Ryan, G. (2016). The importance of the diverse drivers and types of environmental innovation for firm performance. Business Strategy and the Environment, 25(2), 102-119.

Duranton, J., \& Puga, D. (2003). Micro-foundation of urban agglomeration economies in Henderson V. J. and Thisse JF.(eds) Handbook of Regional and Urban Economics 4. Cities and Geography.

Evans, S., Vladimirova, D., Holgado, M., Van Fossen, K., Yang, M., Silva, E. A., \& Barlow, C. Y. (2017). Business model innovation for sustainability: Towards a unified perspective for creation of sustainable business models. Business Strategy and the Environment, 26(5), 597-608.

Fritsch, M. (2002). Measuring the quality of regional innovation systems: A knowledge production function approach. International Regional Science Review, 25(1), 86-101.

Gilsing, V., Nooteboom, B., Vanhaverbeke, W., Duysters, G., \& van den Oord, A. (2008). Network embeddedness and the exploration of novel technologies: Technological distance, betweenness centrality and density. Research Policy, 37(10), 1717-1731.

Horbach, J., Rammer, C., \& Rennings, K. (2012). Determinants of eco-innovations by type of environmental impact. The role of regulatory push/pull, technology push and market pull. Ecological Economics 78, 112-122. 
Jové-Llopis, E., \& Segarra-Blasco, A. (2018). Eco-innovation strategies: A panel data analysis of Spanish manufacturing firms. Business Strategy and the Environment, 27(8), 1209-1220.

Kiefer, C. P., Del Río González, P., \& Carrillo-Hermosilla, J. (2019). Drivers and barriers of eco-innovation types for sustainable transitions: A quantitative perspective. Business Strategy and the Environment. On line, DOI: 10.1002/bse.2246.

Koontz, T. M., Gupta, D., Mudliar, P., \& Ranjan, P. (2015). Adaptive institutions in socialecological systems governance: A synthesis framework. Environmental Science \& Policy, $53,139-151$.

Lundvall, B. Å. (2007). National innovation systems-analytical concept and development tool. Industry and Innovation, 14(1), 95-119.

Marin, G., Marzucchi, A., \& Zoboli, R. (2015). SMEs and barriers to Eco-innovation in the EU: exploring different firm profiles. Journal of Evolutionary Economics, 25(3), 671-705.

Mazzanti, M., \& Zoboli, R. (2006). Economic instruments and induced innovation: the European policies on end-of-life vehicles. Ecological Economics, 58, 318-337.

Melander, L. (2018). Customer and supplier collaboration in green product innovation: External and internal capabilities. Business Strategy and the Environment, 27(6), 677-693.

Novellie, P., Biggs, H., \& Roux, D. (2016). National laws and policies can enable or confound adaptive governance: Examples from South African national parks. Environmental Science \& Policy, 66, 40-46.

Oerlemans, L., \& Meeus, M. (2005). Do organizational and spatial proximity impact on firm performance? Regional Studies, 39(1), 89-104.

Peiró-Signes, Á., \& Segarra-Oña, M. (2018). How past decisions affect future behavior on ecoinnovation: An empirical study. Business Strategy and the Environment, 27(8), 1233-1244.

PITEC (2013). Panel de Innovacion Tecnologica. Fundacion Española para la Ciencia y Tecnologia. https://icono.fecyt.es/PITEC/Paginas/descarga_bbdd.aspx

Porter M., \& Stern S. (2002) National Innovative Capacity. The Global Competitiveness Report, (2001/02)/102-118.

Storper, M., \& Venables, A. J. (2004). Buzz: face-to-face contact and the urban economy. Journal of Economic Geography, 4(4), 351-370.

Tang, M., Walsh, G., Lerner, D., Fitza, M. A., \& Li, Q. (2018). Green Innovation, Managerial Concern and Firm Performance: An Empirical Study. Business Strategy and the Environment, 27(1), 39-51. 
Triguero, A., Mondéjar, M.L., \& Davia, M.A. (2013). Drivers of different types of ecoinnovation in European SMEs. Ecological Economics 92, 25-33.

Triguero, A., Moreno-Mondéjar, L., \& Davia, M. A. (2016). Leaders and laggards in environmental innovation: an empirical analysis of SMEs in Europe. Business strategy and the environment, 25(1), 28-39.

Zubeltzu-Jaka, E., Erauskin-Tolosa, A., \& Heras-Saizarbitoria, I. (2018). Shedding light on the determinants of eco-innovation: A meta-analytic study. Business Strategy and the Environment, 27(7), 1093-1103. 
Table 1. Descriptive Analysis

\begin{tabular}{llllll}
\hline Variables & \multicolumn{5}{c}{ Eco-innovation } \\
& \multicolumn{2}{c}{ O } & \multicolumn{1}{c}{$\mathbf{1}$} & Total firms \\
& $\mathbf{N}$ & $\mathbf{\%}$ & $\mathbf{N}$ & $\mathbf{\%}$ & \\
\hline Eco-innovation & 1285 & 30.1 & 4176 & 69.9 & 5461 \\
Manufacturing & 620 & 22.2 & 2790 & 77.8 & 3410 \\
Services & 665 & 47.9 & 1386 & 52.1 & 2051 \\
Internationalization & 863 & 21.0 & 3232 & 79.0 & 4095 \\
Group & 1274 & 32.4 & 2657 & 67.6 & 3931 \\
Public Funding & 16 & 7.8 & 2022 & 92.2 & 2038 \\
Size: & & & & & \\
$\quad$ 1-9 & 169 & 33.5 & 335 & 66.5 & 504 \\
$\quad$ 10-49 & 516 & 26.5 & 1426 & 73.5 & 1942 \\
$\quad$ 50-249 & 368 & 19.9 & 1480 & 79.1 & 1848 \\
$\quad>250$ & 232 & 19.8 & 935 & 79.2 & 1167 \\
\hline
\end{tabular}


Table 2. Regression Analysis between eco-innovation and Autonomous Community

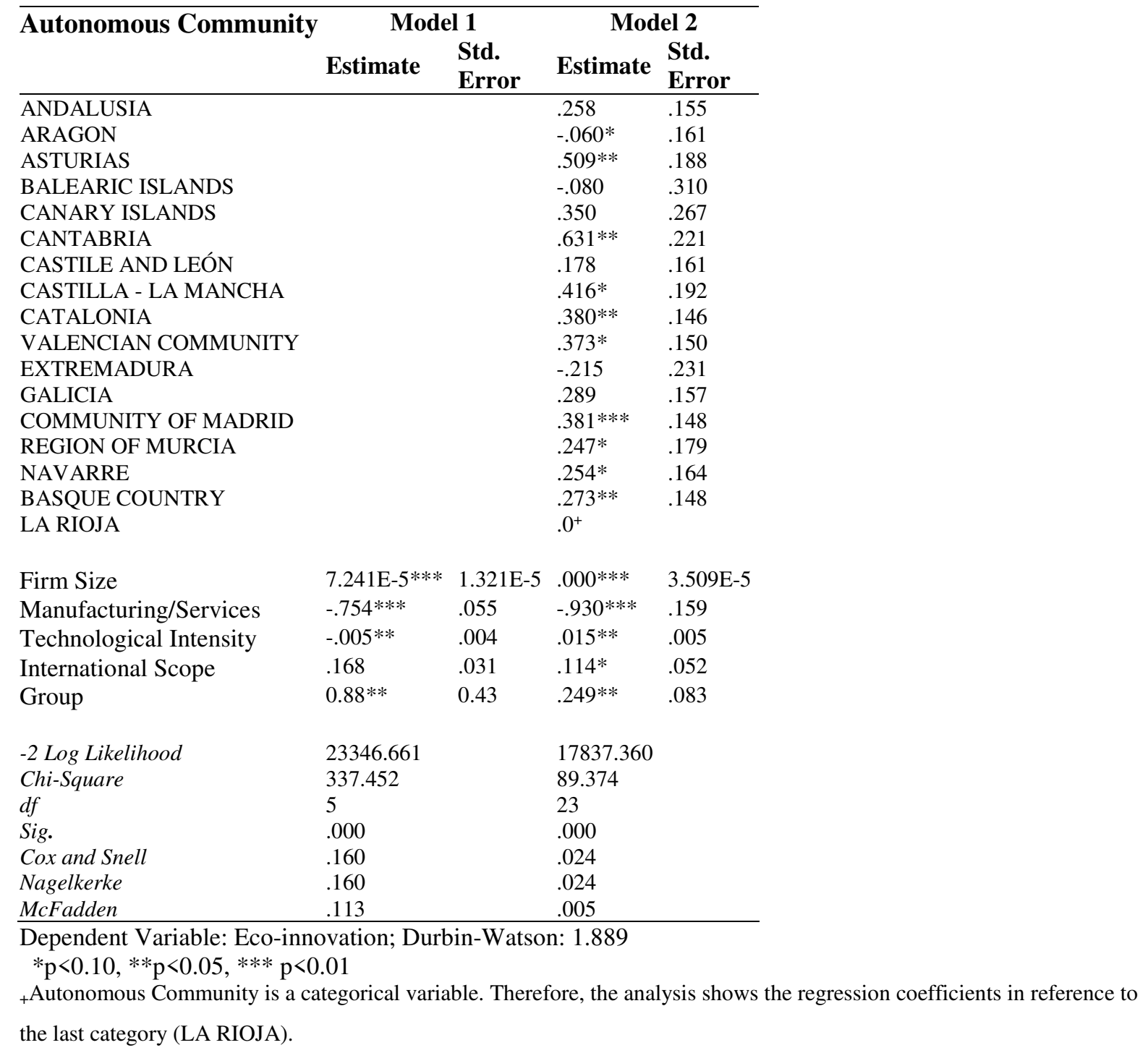


Table 3. Regression Analysis between RIS variables and eco-innovation.

\begin{tabular}{|c|c|c|c|c|c|c|c|c|c|c|c|}
\hline \multirow[t]{2}{*}{ RIS Variables } & \multicolumn{2}{|c|}{ Model 3} & \multicolumn{2}{|c|}{ Model 4} & \multicolumn{2}{|c|}{ Model 5} & \multicolumn{2}{|c|}{ Model 6} & \multicolumn{2}{|c|}{ Model 7} & \multirow{2}{*}{ VIF } \\
\hline & Estimate & Std. Erro & r Estimate & Std. Error & Estimate & Std. Error & \multicolumn{4}{|c|}{ Estimate Std. Error Estimate Std. Error } & \\
\hline Density & & & $.135 * * *$ & .014 & & & & & & & \\
\hline Regional Distance & & & & & .686 & .211 & & & & & \\
\hline Public Financing & & & & & & & $.050 * * *$ & .020 & & & \\
\hline Per capita income & & & & & & & & & $5.307 \mathrm{E}-5$ & $* 1.198 \mathrm{E}-5$ & \\
\hline Firm Size & \multicolumn{2}{|c|}{$7.241 \mathrm{E}-5 * * * 1.321 \mathrm{E}-5$} & $.010 * * *$ & 4.604E-5 & $.009^{* * *}$ & $2.302 \mathrm{E}-5$ & $.008 * * *$ & $4.682 \mathrm{E}-5$ & $.008 * * *$ & $4.682 \mathrm{E}-5$ & 1.034 \\
\hline Manufacturing/Servi & es-.754*** & .055 & $-.690 * * *$ & .078 & $-.825 * * *$ & .069 & $-.739 * *$ & .080 & $-.739 * *$ & .080 & 1.112 \\
\hline Technological Inten & $y-.005 * *$ & .004 & $-.016^{*}$ & .005 & $-.014 * *$ & .004 & $-.016 * *$ & .005 & $-.016 * *$ & .005 & 1.156 \\
\hline International Scope & .168 & .031 & .068 & .045 & .070 & .040 & .077 & .045 & .077 & .045 & 1.263 \\
\hline Group & $0.88^{* *}$ & 0.43 & $.024 *$ & .011 & $.064 * *$ & 0.28 & $.092 * *$ & .054 & $.092 * *$ & .054 & 1.302 \\
\hline -2 Log Likelihood & \multicolumn{2}{|l|}{23346.661} & \multicolumn{2}{|c|}{19431.311} & \multicolumn{2}{|l|}{17636.114} & \multicolumn{2}{|c|}{25003.467} & \multicolumn{3}{|c|}{21001.125} \\
\hline Chi-Square & \multicolumn{2}{|l|}{337.452} & \multicolumn{2}{|l|}{290.315} & \multicolumn{2}{|l|}{270.870} & \multicolumn{2}{|l|}{316.756} & \multicolumn{3}{|l|}{283.710} \\
\hline$d f$ & \multirow{2}{*}{\multicolumn{2}{|c|}{$\begin{array}{l}5 \\
.000\end{array}$}} & \multirow{2}{*}{\multicolumn{2}{|c|}{.000}} & \multirow{2}{*}{\multicolumn{2}{|c|}{.000}} & \multirow{2}{*}{\multicolumn{2}{|c|}{$\begin{array}{l}0 \\
.000\end{array}$}} & \multirow{2}{*}{\multicolumn{3}{|c|}{$\begin{array}{l}6 \\
.000\end{array}$}} \\
\hline Sig. & & & & & & & & & & & \\
\hline Cox and Snell & \multicolumn{2}{|l|}{.160} & \multicolumn{2}{|l|}{.160} & \multicolumn{2}{|l|}{.172} & \multicolumn{2}{|l|}{.165} & \multicolumn{3}{|l|}{190} \\
\hline Nagelkerke & .160 & & .160 & & .172 & & .165 & & .189 & & \\
\hline McFadden & \multicolumn{2}{|l|}{.113} & \multicolumn{2}{|l|}{.112} & \multicolumn{2}{|l|}{.115} & \multicolumn{2}{|l|}{.113} & \multicolumn{3}{|l|}{.119} \\
\hline
\end{tabular}

Dependent Variable: Eco-innovation; Durbin-Watson: 1.917

$* \mathrm{p}<0.10, * * \mathrm{p}<0.05, * * * \mathrm{p}<0.01$ 